\title{
Erratum to: On absolute linear instability analysis of plane Poiseuille flow by a semi-analytical treatment
}

\author{
Nemat Dalir $^{1} \cdot$ S. Salman Nourazar ${ }^{1}$
}

Published online: 27 June 2017

(C) The Brazilian Society of Mechanical Sciences and Engineering 2017

Erratum to: J Braz. Soc. Mech. Sci. Eng. (2015)

37:495-505

DOI 10.1007/s40430-014-0187-2

The original version of this article unfortunately contained a mistake.

At the reference section of the original article, reference number [20] was incorrect. The DOI number was incorrectly printed as $10.1007 / \mathrm{s} 4043001300573$. The reference should be revised as follows: Gennaro EM, Simões LGC, Malatesta V et al. J Braz Soc Mech Sci Eng 36:59 (2014). doi:10.1007/s40430-013-0057-3.

The online version of the original article can be found under doi:10.1007/s40430-014-0187-2.

S. Salman Nourazar

icp@aut.ac.ir

Nemat Dalir

dalir@aut.ac.ir

1 Department of Mechanical Engineering, Amirkabir University of Technology, 158754413 Tehran, Iran 